\title{
Study on the Construction and Utilization of Artistic Network Teaching Resources in the Background of Internet +
}

\author{
Haolin Liao \\ College of Arts and Media, Sichuan Agricultural University, Sichuan, Ya’an, 625014
}

Keywords: Internet +, Artistic Network Teaching Resource, Construction

\begin{abstract}
The construction of teaching resources is the basis of educational information, its connotation is to attach importance to the quality of digital teaching resources and the use of network information resources, information technology as an important means to improve the quality of teaching, to strengthen the sharing of quality teaching resources. Art institutions of information construction than ordinary institutions late, and because of its teaching content, patterns and resources of various types of characteristics, to the network resource construction has brought greater challenges. Through the analysis of the status quo of the network teaching resource library of art colleges and universities, this paper puts forward the basic principles and construction ideas of the resource library, and discusses the main contents of the resource library.
\end{abstract}

\section{Introduction}

Network teaching resources are specifically related to the teaching content of the network resources, in essence, the network teaching resources are mainly text class, graphic image class, audio class, video class and animation class five categories. Among them, the text resources due to the rich content, less space, fast delivery, timeliness and other characteristics, has become an important carrier of information dissemination and teacher and student communication; graphic image material because of its visual effects of visualization is to become daily teaching Audio and video materials are mainly narrative recording, reading and recording, music songs, etc., is the general teaching students to improve language skills and listening to an important tool, but also music, music, music, music, music, music, music, Dance, music and other professional teaching important content; video material mainly performance video, video, film, feature film, etc., in the drama, opera, film commentary and other professional use in the most extensive; animation mainly refers to two-dimensional animation and Three-dimensional animation, is now in the advertising, the results show, virtual reality and other fields play an extremely important role. In the classroom, the majority of teachers can make full use of text, images, sound, video, animation and other media to show, simulate the scene, to provide a vivid picture, so that students "immersive" to obtain more intuitive sensibility The knowledge. In a complete network teaching environment, the most basic is the network teaching resource library. Which is the resource management system for the management of resources storage, sharing and use; Second, parallel with the network is to support the teaching process platform, teaching platform is above the user-oriented portal. If there is no network teaching resources, it is equivalent to the network teaching "no rice without water", even reckless "daughter" will not make delicious "food".

\section{The Necessity of Constructing the Network Teaching Resource Library of Art Colleges}

With the deepening of the reform of the educational talents and the reform of the curriculum system, the teaching methods, contents and management of the art class have changed greatly. Due to the rapid development of information technology, students access to knowledge from the traditional classroom, books extended to the network. Art professional theory teaching and ability 
training is very practical, most of the teaching of the discipline should be in practice to learn, in the process, more and more teachers use information technology to assist the art class teaching. At the same time, in recent years, the integration of information technology and art has become increasingly close. Therefore, the development of art institutions, building a high level of professional network teaching resource library is very necessary [1], the main reasons are as follows: (1) to promote quality teaching resources sharing. Most of the colleges and departments of the Nanjing Art Institute have realized the importance of the network teaching resource base, all put human and material resources to carry on the construction of teaching resource base, and already have certain achievements. However, there are often overlapping disciplines between art colleges and universities, such as the School of Music and the School of Music, the Media Institute and the Shangmei College, the Design Institute and the School of Industrial Design, all have similar teaching content, and establish a unified school with schools rather than colleges The standard teaching resource platform can avoid duplication of resources, so that high-quality resources to share the school even to achieve inter-school sharing.

To broaden the form of art teaching, to provide independent learning platform. The traditional art teaching method is to teach teachers as the main body of knowledge and skills, in recent years, the integration of art teaching and information technology increasingly close, the teaching model also changes. Through the construction of the network teaching resource library, the use of information technology to integrate all kinds of teaching resources, on the one hand enriched the form of art teaching, to achieve a diversified teaching model, on the other hand, with interactive, autonomy, practical characteristics of the resource platform Can provide students with a wealth of learning materials, is conducive to cultivating students the ability to self-study, and to promote communication between students and teachers and communication.

The integration of special artistic resources information, to achieve the rational use of the resources of our school. Art institutions have rich artistic teaching resources, these resources in various forms, is the art school teachers accumulated long-term discipline essence. Reasonable and full use of the school has the art of teaching resources, its information integration, into a network of resources, is conducive to creating a great artistic institutions of their own characteristics of the teaching resource library.

\section{The Status Quo and Problems of Network Teaching Resources Construction}

At present, China's education information in the prevalence of "re-construction, light applications, heavy hardware, light software," the phenomenon of the training of teachers, internal resources, as well as the allocation of network resources and teaching platform, not enough attention, education information There is a problem of investment imbalance, especially the lack of digital resources, has become a bottleneck restricting the efficient and rapid development of educational information. As the core of educational information teaching resources, education is the process of information in the top priority. In the higher art institutions, although most of the establishment of their own teaching site, but the site content is really a small part of the teaching resources; some colleges and universities may be relatively rich in teaching resources, but the storage of scattered, different standards, Lack of the necessary teaching platform for its integration, the majority of teachers and students in the search and use of these teaching resources, there is a great inconvenience; there are colleges and universities despite the introduction of the network teaching platform, but still similar to "shell" One, teaching resources like empty.

Although some colleges and universities to build or purchase a certain network of teaching resources, but need to improve and improve the problem is still a lot. Such as "heavy quantity of light quality"; teaching courseware to the public class, teaching aids mainly, while the main courses and professional courses are relatively small; network online curriculum coverage is narrow; targeted is not strong; poor practical; Take our college, the first half of 2008, our hospital introduced the "Tsinghua Education Online" network-assisted teaching platform, but due to a variety of objective factors, so far, the entire teaching resource library in addition to the purchase of some resources, I The original teaching resources of the teachers are still empty, only a very small part of 
the teacher's teaching plan, syllabus or a small amount of courseware, and for dance, drama, opera, music, art, design and other professional needs of multimedia teaching resources , It is very few or almost no. 2.3 Higher art institutions are rich in teaching resources, but the network teaching resources are relatively small. At present, both the library, the audio-visual center or the secondary colleges, or the Institute, have autographed, developed or purchased a large number of audio and video tapes, CD, DVD and other teaching materials and electronic books, electronic journals and Chinese and foreign languages database, paper The quality of teaching materials is the scale of the second section, the teaching resources of each unit also have their own characteristics, different shapes, thus building a unique art institutions unique teaching resource library. However, these materials because there is no timely digital conversion or format conversion, compression processing, has not been uploaded to the online server, resulting in the lack of network teaching resources, teachers and students can learn from or use of network teaching resources is extremely inadequate, severely restricted the network Teaching the development and development.

\section{Construction and Content of Art Network Teaching Resource}

Purchase a mature business resource library. The business resource library provided by the third party is an important part of the construction of the resource library. The resource library does not need to participate in the development of the school, you can directly buy the use of convenient, and highly professional, many types of resources, a large number of teachers and students to meet the basic needs. For example, the library used by the library music library, superstar academic video, the new Oriental multimedia learning library are representatives of such a library, these resources greatly expand the number of resources in the use of the process has achieved good results. It is worth noting that the quality of the commercial arts library on the market varies greatly. Therefore, we must do a good job pre-research, carefully select the applicable product.

Strengthen self - development, build the characteristics of art institutions library. The commercial resource library is an indispensable part of the teaching resource library of art colleges, but it is not enough to use the commercial resource library only because of its obvious shortcomings, including: (1) the content of the commercial resource library is single, out of teaching, sometimes It is difficult to meet the actual needs of teachers and students; (2) the use of different companies to develop the resource library is often difficult to achieve compatibility and style of unity; (3) dynamic is not strong, difficult to achieve follow-up independent updates. Art institutions have a large number of unique resources scattered in the hands of teachers, such resources are teaching first-hand information, and teaching practice closely, practical and strong, need to be fully and rationally used. Schools should mobilize the enthusiasm of teachers, mobilize teachers to participate in resource collection, and set up a special development team, regularly collect school resources, resource conversion, processing and follow-up updates to build a practical, characteristic school-based resource library.

Art institutions and software companies jointly developed. It is difficult to compare the characteristics of the commercial resource library by the art institutions. However, due to the limitation of the professional limit, the art institutions lack the corresponding technical resources compared with the science and engineering colleges. Most professional teachers do not have the information technology level High, for the independent development of great difficulties. The use of schools and software companies jointly developed the way, on the one hand can make the first line of teachers to participate in the database construction, to ensure the applicability of resources, characteristics, on the other hand, professional software companies to provide technical support to ensure that the quality of resources, But also on the teachers of technical training, so that teachers can accumulate experience, master the skills for further development in the future to lay the foundation for further development.

Case training resource library. Artistic teaching has a very strong practical characteristics, the establishment of case training resource library is essential, its existence is to meet the "combination of work and study" requirements, including two major components, one is a complete project and 
case-based Teaching project library (training project package, teacher teaching case, etc.), the second is the industry, enterprise resource module (related professional industry standards, industry status, industry development trends, corporate recruitment information, school-enterprise cooperation, etc.).

Teaching results resource library. Teaching achievement is the essence of art institutions, including projects, monographs, papers, research reports, teaching materials, patents and so on. The establishment of a library of teaching results can achieve long-term retention and wide sharing of results, improve the scope and intensity of the results, so that it can play a better reference, promote the role of improving the quality of art institutions have a positive impact.

Qualification Resource Library. Professional qualification is also an important part of the educational resource library, which helps students to carry out professional qualification. The contents include professional assessment standards and policies and regulations, art professional examination resources package (training plan, training content, all kinds of test questions library, online simulation test system, etc.) and other related learning resources.

\section{Conclusion}

The purpose of constructing high-quality teaching resources and the development of network teaching resources is to realize the sharing and dissemination of high-quality teaching resources by using multimedia and network technology, to promote the interaction of teachers and students at high levels, to promote active, cooperative, The formation of an open and efficient teaching model, to better develop students' information literacy and problem-solving ability and innovation. In the construction of the entire network resources, we should pay attention to the actual changes in the dynamic supplementary teaching resources, only "advancing with the times", will continue to improve the original resources, to ensure that the "tree of life" evergreen, high art institutions Of the professional teaching and other teaching work will be on a new level.

\section{References}

[1] Li Yuanqing. Network teaching resources in the training of doctoral students in the application of [J]. Leadership Science Forum. 2017 (15)

[2] Tan Jing. High-quality network teaching resources application strategy [J]. Education of the times. 2017 (17)

[3] Guo Yi. On the network teaching resources construction thinking [J]. Science and Technology Outlook. 2015 (25)

[4] Geng Weijiang. Exploring the construction and application of network teaching resources [J] .Journal of Shandong Industrial Technology. 2016 (01)

[5] Yu Xin. Network teaching resources construction [J]. Small and medium-sized enterprise management and technology (late). 2014 (03)

[6] Yu Xin. Research on the Guarantee Mechanism of Network Teaching Resources Construction and Use [J]. Journal of SME Management and Technology. 2014 (03) 